Case Report

\title{
THE USE OF KETAMINE, XYLAZINE AND MIDAZOLAM COMBINATION FOR TOTAL INTRAVENOUS ANESTHESIA (TIVA) IN SURGICAL REMOVAL OF ABDOMINAL TESTIS AT STALLION
}

\author{
Bojan D. Toholj ${ }^{1}$, Velibor D. Kujača ${ }^{1}$, Milenko R. Stevančević ${ }^{1}$, \\ Jovan M. Spasojević ${ }^{1}$, Ozren B. Smolec ${ }^{2}$ \\ ${ }^{1}$ University of Novi Sad, Faculty of Agriculture, Department of Veterinary Medicine, \\ Trg Dositeja Obradovica 8, 21000, Novi Sad, Serbia \\ ${ }^{2}$ University of Zagreb, Faculty of Veterinary Medicine, Heinzelova 5, Zagreb, Croatia
}

Received 16 June 2014; Received in revised form 19 August 2014; Accepted 25 August 2014

\begin{abstract}
Equine veterinarians frequently anesthetize horses. In majority of cases performing short-term anesthesia (duration, 20 minutes). But there is substantial need for long term anesthesia. The aim of this work is to present our experience with a long term and short term total intravenous anesthesia in horses. In this paper we are presenting results of anesthesia monitoring of a horse undergoing surgical remove of an abdominal testis (complete abdominal cryptorchid). Sedation of the horsewas conducted with xylazine, $1.0 \mathrm{mg} / \mathrm{kg}$, iv, and midazolam $0.06 \mathrm{mg} / \mathrm{kg}$, iv. The total anesthesia was induced using a combination of ketamine $2.2 \mathrm{mg} / \mathrm{kg} / \mathrm{iv}$, and midazolam $0.1 \mathrm{mg} / \mathrm{kg} / \mathrm{iv}$. After induction the horse was restrained and anesthesia was maintained with continuous intravenous drip of a combination of drugs mixed in infusion bottle with midazolam $(0.002 \mathrm{mg} / \mathrm{kg} / \mathrm{min})$, ketamine $(0.03 \mathrm{mg} / \mathrm{kg} / \mathrm{min})$, and xylazine $(0.016 \mathrm{mg} / \mathrm{kg} / \mathrm{min})$. Additional ketamine $(0.03 \mathrm{mg} / \mathrm{kg})$ and midazolam $0.03 \mathrm{mg} / \mathrm{kg} / \mathrm{iv}$ was administered if the horse moved its head or limbs during the procedure. The duration of anesthesia was 90 minutes. During this time cardiopulmonary parameters and reflexes were monitored continuously.The recovery of anesthesia was 30 minutes and horse stood on the first attempt 40 minutes. Midazolam, ketamine, and xylazine in combination produced TIVA in this horse and can be used for short term, middle term, and longer lasting surgical procedures in the field.
\end{abstract}

Key words: horse, anesthesia, TIVA

\section{INTRODUCTION}

Equine practitioners frequently anesthetize horses. In the majority of cases this is of short duration (20 minutes) (1). Moreover field anesthesia is best suited for short term surgical procedures to minimize risk of complications from ventilation/ perfusion mismatch and hypoxemia, and minimize the risk of post anesthetic myopathies resulting from compartment crush syndrome (2). However, there are substantial needs to produce longer

Corresponding author: Assist. Prof. BojanToholj, $\mathrm{PhD}$

E-mail address: bojantoholj@gmail.com

Present address: Department of veterinary medicine,

Faculty of Agriculture, Trg Dositeja Obradovića 8,

21000 Novi Sad, Serbia

Phone: +381214853481

Copyright: (C) 2014 Toholj B. This is an open-access article published under the terms of the Creative Commons Attribution License which permits unrestricted use, distribution, and reproduction in any medium, provided the original author and source are credited.

Competing Interests: The authors have declared that no competing

interests exist.

Available Online First: 15 September 2014

http://dx.doi.org/10.14432/j.macvetrev.2014.09.024 term anesthesia for long term surgical procedures (laparatomy etc.). General anaesthesia in a horse, especially long term anesthesia carries a risk, which is often higher than that of other domestic species. It is therefore important to try and minimize these risks as much as possible when performing any procedure. Problems can be encountered at any stage of the anaesthetic. The general anesthesia can be a challenge on field surgery because there are needs for improvisation of restraining, creating a optimal condition in variable surroundings. Horses should be fasted for 6-12h prior to anesthesia to allow for the reduction of abdominal fill in an effort to limit compression of the diaphragm by the hindgut and decrease ventilation/perfusion mismatching (3). The anesthetic protocol should be divided as premedication, induction, maintenance and recovery phases. For all these phase proper drugs or combination of drugs must be used to proper hypnosis, myorelaxation and analgesia. These combinations usually include an injectable anesthetic (ketamine, propofol), an alpha2 agonist, in combination with benzodiazepines and opioids. 
Guaiphenensine is often used as central myorelaxant in TIVA combination (4), but it's not always available. Local anesthesia should be considered and used in every case in order to use lower doses of other drugs.

The aim of this work is to present our experience with a long term and short term total intravenous anesthesia in a horse using a ketamine/xylazine midazolam combination.

\section{MATERIALS AND METHODS}

In this paper we are presenting results of anesthesia monitoring of a horse undergoing a surgical remove of abdominal testis (complete abdominal cryptorhid). Sedation of the horse was conducted with xylazine (Xylapan ${ }^{\circledR}$ Vetoquinol, UK), $1.0 \mathrm{mg} / \mathrm{kg}$, iv, and midazolam (Dormicum ${ }^{\circledR}$, Roche) $0.06 \mathrm{mg} / \mathrm{kg} / \mathrm{iv}$, (Table 1). The general anesthesia was induced using a combination of ketamine $2.2 \mathrm{mg} / \mathrm{kg} / \mathrm{iv}$ and midazolam $0.1 \mathrm{mg} / \mathrm{kg} / \mathrm{iv}$. After induction the horse was restrained and anesthesia was maintained with continuous intravenous drip of a combination of drugs mixed in infusion bottle with midazolam $(0.002 \mathrm{mg} / \mathrm{kg} / \mathrm{min})$, ketamine $(0.03$ $\mathrm{mg} / \mathrm{kg} / \mathrm{min}$ ) (Ketamidor, Richter pharma), and xylazine $(0.016 \mathrm{mg} / \mathrm{kg} / \mathrm{min})$ (MKX-combination). The drugs for continuous intravenous drip were prepared in infusion bottle of $500 \mathrm{ml} 0,9 \% \mathrm{NaCl}$ (Hemofarm ${ }^{\mathrm{TM}}$, SRB) by adding: $1350 \mathrm{mg}$ ketamine (13.5 ml 10\% Ketamidor $^{\circledR}$, Richter Pharma, AU), 720 mg xylazine (36 ml 2\% Xylapan ${ }^{\circledR}$, Vetoquinol, UK) and $90 \mathrm{mg}$ of midazolam (6 ampulae of Dormicum ${ }^{\circledR}$, Roche, $\mathrm{CH}$, $1 \mathrm{amp}=3 \mathrm{ml}=15 \mathrm{mg})$. The infusion rate was set at $6 \mathrm{ml} / \mathrm{min}(120 \mathrm{drops} / \mathrm{min}$ in standard infusion drip system). Additional ketamine $(0.03 \mathrm{mg} / \mathrm{kg})$ and midazolam $0.03 \mathrm{mg} / \mathrm{kg} / \mathrm{iv}$ was administered if the horse moved its head or limbs during the procedure.
The patient was a three years old, $500 \mathrm{~kg}$ weighted stallion. A couple days before surgery the stallion underwent a clinical examination which reveal the absence of the left testicle in the scrotum. The clinical examination was conducted in the usual manner in order to asses a health condition and operation risk. The blood parameters (CBC) and general metabolism parameters (serum protein, serum albumin, creatinine) were in normal ranges. Ultrasound examination were conducted in order to asses a position and size of cryptorchid testis, and to prepare the best operative planning. We couldn't identify testicle in inguinal region, and operation plan included a parainguinal laparotomy and manual exploration of abdominal cavity.

\section{RESULTS}

After premedication a status of sedation were mild. The horse was standing with head moved down. The horse was moved to a stall bedded with straw with a plastic cover prior to induction of general anesthesia. After induction of general anesthesia the horse was pulled on its side and positioned in dorsal decumbency. The legs of the horse were taught with ropes. The operation field was prepared in usually manner.

The duration of anesthesia was 90 minutes. During this time a cardiopulmonary parameters and reflexes were monitored continuously (Table 2). The mean pulse rate value was $28 \pm 1.41 / \mathrm{min}$. The mean breath rate was $8 \pm 0.51 / \mathrm{min}$. The pulse was always fully or easily palpable. After induction the type of breathing was costal, and after 10 minutes of maintenance starting switched to diaphragmatic. Capillary refill time (CRT) was $2 \mathrm{sec}$ throughout

Table 1. Drug combination used for equine field anesthesia

\begin{tabular}{lll}
\hline Premedication $\mathbf{~ m g} / \mathbf{k g} / \mathbf{i v}$ & Induction $\mathbf{~} \mathbf{g} / \mathbf{k g} / \mathbf{i v}$ & Maintance $\mathbf{~} \mathbf{g} / \mathbf{k g} / \mathbf{m i n} / \mathbf{i v}$ \\
\hline xylazine, 1.0 & ketamine 2.2 & midazolam 0.002 \\
midazolam 0.06 & midazolam 0.1 & ketamine 0.03 \\
& & xylazine 0.016 \\
\hline
\end{tabular}

During the time of anesthesia cardiopulmonary parameters and reflexes were monitored continuously, and recorded (Fig. 1, anesthetic protocol). These parameters included: pulse rate and quality, breath rate, type and depth, capillary refill time, mucous membranes color, palpebral, corneal, pupilary and anal sphincter reflexes. the procedure. The weak palpebral reflex was present almost continuously, also as corneal reflex. Recovery of anesthesia was 30 minutes and horse stood on first attempt (Table 3). During the procedure additional ketamine and midazolam were administered because of nystagmus and $\mathrm{r}$ movement of head. 
Table 2. Cardiovascular, pulmonary and reflexes monitoring

\begin{tabular}{|c|c|c|c|c|c|c|c|c|c|c|c|c|c|c|c|c|c|c|}
\hline \multirow[b]{2}{*}{ Parameters } & \multicolumn{18}{|c|}{ Time (min) } \\
\hline & 5 & 10 & 15 & 20 & 25 & 30 & 35 & 40 & 45 & 50 & 55 & 60 & 65 & 70 & 75 & 80 & 85 & 90 \\
\hline Pulse & 28 & 34 & 28 & 28 & 28 & 28 & 28 & 28 & 28 & 28 & 28 & 28 & 28 & 28 & 28 & 28 & 28 & 28 \\
\hline Pulse quality & 3 & 3 & 3 & 3 & 3 & 3 & 3 & 3 & 3 & 3 & 3 & 2 & 2 & 2 & 2 & 2 & 3 & 3 \\
\hline Breath/min & 8 & 10 & 8 & 9 & 8 & 8 & 8 & 8 & 8 & 8 & 8 & 8 & 8 & 8 & 8 & 8 & 8 & 8 \\
\hline Type of breath & $\mathrm{c}$ & $\mathrm{c}$ & d & d & $\mathrm{d}$ & $\mathrm{d}$ & $\mathrm{d}$ & $\mathrm{d}$ & $\mathrm{d}$ & $\mathrm{d}$ & $\mathrm{d}$ & $\mathrm{d}$ & $\mathrm{d}$ & $\mathrm{d}$ & $\mathrm{d}$ & d & $\mathrm{d}$ & $\mathrm{d}$ \\
\hline $\mathrm{CRT} / \mathrm{sec}$ & 2 & 2 & 2 & 2 & 2 & 2 & 2 & 2 & 2 & 2 & 2 & 2 & 2 & 2 & 2 & 2 & 2 & 2 \\
\hline Palpebral reflex & + & + & + & + & - & + & + & + & + & + & + & + & + & + & - & + & + & + \\
\hline Corneal reflex & + & + & + & + & - & - & - & - & + & + & + & + & + & + & + & + & + & + \\
\hline Nistagmus & & & & & & & & & & & & & & & & & & \\
\hline Hed movement & - & - & - & - & - & - & - & + & - & - & - & + & - & - & - & - & - & - \\
\hline $\begin{array}{l}\text { Additional ketamine/ } \\
\text { midazolam }\end{array}$ & - & - & - & - & - & - & - & + & - & - & - & + & - & - & - & - & - & - \\
\hline
\end{tabular}

\section{DISCUSSION}

General anesthesia is mandatory for many surgical procedures in horses which require the patient to be immobile, unaware, and without pain. They frequently can be a challenge in the field because there are many obstacles and effort must be made to provide adequate bedding, positioning, light, aseptic conditions, etc. There are three major components of general anesthesia which must be achieved: hypnosis, analgesia and muscle relaxation. Numerous of drugs can be used to achieve these demands. Many of drugs can produce cardiovascular and pulmonary depression. These must be considered in field surgery where intubation and mechanical ventilation, and oxygen supplementation are not available. In the described case cardiovascular and pulmonary depression were minimal. The horse spontaneously breathed throughout the procedure, and pulse rate was

Table 3. Recovery monitoring

\begin{tabular}{ll}
\hline Parameter & Minutes \\
\hline First movement & 4 \\
First movement of head and neck & 5 \\
Time to first attempt to stand & 25 \\
Time to standing & 30 \\
Time to walking & 40 \\
\hline
\end{tabular}

normal, with no or little increasing of pulmonary excursion during a time of intensive pain (incision, funiculus spermaticus ligating). In another study with six healthy Thoroughbred horses Hubbell (2) used a MKX combination and found no significantly disturbance of cardiovascular and metabolic parameters.

Many other combinations of drugs can be used for achieving TIVA at horses. Muir (5) investigated the quality of four combinations of drugs and found that the quality of induction, muscle relaxation and analgesia was not significantly different among groups, but thiopental/ketamine/detomidine combination had a poorer recovery from anesthesia, often requiring assistance to stand. In our case the first movement after turning off infusion was marked at fourth minutes after, and the first movement of head and neck was observed at 5 minutes. The first attempt to stand was at 30 minutes, and the horse stood at 40 minutes and walked without assistance after 45 minutes.

The major complications encountered during equine field anesthesia are hypoxemia and postanesthetic myopathies and neuropathies. Careful attention should be given to protecting pressure points over the shoulders and or hips, and when possible, padding should be placed under these areas (2). In our case we used straw bales for bedding, covered with plastic overlap to provide a comfort level as much as possible. 


\section{CONCLUSION}

Total intravenous anesthesia of horses can be achieved using a combination midazolam, ketamine, and xylazine. This combination can be used for short term, middle term and long lasting surgical procedures in on field surgery, and causing minimal cardiovascular and pulmonary depression.

\section{REFERENCES}

1. Hubbell, J. A., Aarnes, T. K., Lerche, P., Bednarski, R. M. (2012). Evaluation of a midazolamketamine-xylazine infusion for total intravenous anesthesia in horses. Am J Vet Res. 73, 4, 470-475. http://dx.doi.org/10.2460/ajvr.73.4.470 PMid:22452492

2. Caulkett, N. (2007). Equine field anesthesia. Veterinary rounds, 7, 9, 112-117.
3. Taylor, PM., Clarke, KW. (1999). Intravenous anesthesia. In: Handbook of equine anesthesia. London: Harcourt Brace; 33-54.

http://dx.doi.org/10.1097/00000542-199904001-00058

4. Taylor, PM., Luna, SPL., White, KL, (2001). Intravenous anaesthesia using detomidine, ketamine, and guaiphenesin for laparotomy in pregnant pony mares. Vet Anaesth Analg. 28, 119-125.

http://dx.doi.org/10.1046/j.1467-2987.2001.00046.x

5. Muir, W., Lerche, P., Robertson, J. T., Hubell, A. E., Beard, W., Miller, T., Badgley, B., Bothwell, V. (2000). Comparison of four drug combinations for total intravenous anesthesia of horses undergoing surgical removal of an abdominal testis. J. Am Vet Med Assoc. 217, 6, 869 - 873.

http://dx.doi.org/10.2460/javma.2000.217.869

Please cite this article as: Toholj B., Kujača V., Stevančević M., Spasojević J., Smolec O. The use of ketamine, xylazine and midazolam combination for total intravenous anesthesia (TIVA) in surgical removal of abdominal testis at stallion. Mac Vet Rev 2014; 37 (2): 185-188. http://dx.doi.org/10.14432/j.macvetrev.2014.09.024 